\title{
DÜBLIN
}

Technological University Dublin ARROW@TU Dublin

\section{Considering a Complemental Model of Health and Fitness}

Ross Neville

ross.neville2@student.dit.ie

Follow this and additional works at: https://arrow.tudublin.ie/tfschhmtart

Part of the Sports Sciences Commons

\section{Recommended Citation}

Neville, R.D. (2012) Considering a complemental model of health and fitness, Sociology of Health \& Illness. doi:10.1111/j.1467-9566.2012.01494.x

This Article is brought to you for free and open access by the School of Tourism \& Hospitality Management at ARROW@TU Dublin. It has been accepted for inclusion in Articles by an authorized administrator of ARROW@TU Dublin. For more information, please contact arrow.admin@tudublin.ie, aisling.coyne@tudublin.ie, gerard.connolly@tudublin.ie.

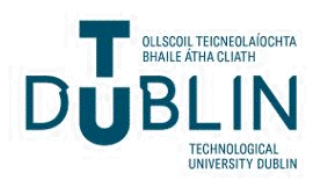




\title{
Review article \\ Considering a complemental model of health and fitness Ross D. Neville
}

\author{
College of Arts and Tourism, Dublin Institute of Technology, Ireland
}

\begin{abstract}
This article examines the concept of fitness, which, in spite of its much avowed cultural significance, has become the subject of much critical attention. In particular, it considers the now contested relation of fitness to health; the fact that, although there appears to be a clear consensus on a simple causal relation between the two, this has been deemed illusory outside the medico-scientific context of its production. In response to the problems with both of these positions, this article examines the potential for reconfiguring the relation between fitness and health on new terms. A complemental model of health and fitness is proposed; one that strives to account for the body's objective and subjective dimensions and for those intermediary varieties of experience that lie in between.
\end{abstract}

Keywords: health and fitness, complemental model, complemental curve, intermediary varieties of experience

\section{Introduction}

In spite of its avowed cultural significance and much as it continues to be legitimated by the fields of health and medicine, the concept of fitness has been the subject of much critical attention of late. On the one hand, it is clear that our imagination as academics, policymakers, and legislators has been captured by the promise of fitness. That is to say, on the basis of the seemingly incontrovertible evidence that physical activity and exercise contribute in a simple causal manner in improving health, it is now commonly thought that fitness is the most desirable state of the individual's body in modern society - something akin to the new health - and promises nothing less than new and improved standards of wellbeing in the public domain. On the other hand, however, this emphasis on fitness (particularly individual fitness) has been deemed to be problematic. Critical accounts have tended to emphasise the politically driven dimensions of these ostensibly natural facts, the alignment of the public-private divide in the service of economic interests which the fitness industries now clearly engender, and the subsequent privatisation of socially borne risk. If, as Freund and Martin (2004) suggested, fitness is best understood in relational terms, then what fitness is related to on these critical accounts is mere consumption activity and is, therefore, quite separate from the aforementioned progressive convictions to improving health and enhancing wellbeing.

One broad concern that is worth highlighting at the outset is the fact that these opposing accounts of fitness have typically come from functionally separated spheres of the academy. 
And on this basis, there appears to have been little in the way of exchange (not to mention confluence) of opinion. Debates about the relative merits of fitness and its relation to health fall into two categories. On the one hand there is no debate about the relation between fitness and health because the supporting medico-scientific evidence makes this relation so selfevident. On the other, debates are couched in a language so abstract that the possibility of external critique is excluded. In spite of the presence of this impasse constraining disciplinary discourse, however, the main concern in this article is to engage both these perspectives in a work of retrieval and, in particular, to examine the now contested relation of fitness to health. The purpose of this article is to argue that both these perspectives are insufficient, and that what is needed is neither uncritical praise nor root-and-branch condemnation. Borrowing a phrase from Latour (2004a), there is a need for refocusing attention towards matters of concern.

The first two sections of this article take issue with both the attribution of a simple causal relation between fitness and health and its opposition, the notion that this is merely illusory. On the basis of the shortcomings of both these accounts, and in order to work towards an alternative position with respect to the relation of fitness and health, the final two sections of this article explore the possibilities for, and implications of, reconfiguring this relation on complemental terms. A complemental model of health and fitness is offered, both as a means of reconciling this critical impasse and as an avenue for future research concerning the variegated structuring of bodily experience.

\section{The promise of fitness}

In a specific sense, the significance attributed to fitness is undeniable and the economic strength of the fitness industry is typically cited as a measure of its cultural value. For example, it has experienced steady growth over the past four decades in line with a large-scale decline of membership in more traditional social and community-based organisations. Over recent years, in particular, the fitness industry has come to the fore as the leading segment of the leisure facilities sector (Datamonitor 2010). According to the International Health, Racquet and Sportsclub Association (IHRSA), over 128,000 clubs served approximately 119 million members in the year 2009, many of whom, despite the current economic climate, were new members (IHRSA 2010). It is difficult to think of another sector of the leisure industries which, given such unfavourable economic conditions, shows such a strong growth trend. ${ }^{1}$

In spite of this, it would be a perverse misunderstanding of the magnitude of fitness to consider it in mere quantitative terms. As one of the most commonly visited sites for recreational consumption, for example, the fitness club industry has emerged as a powerhouse in international commercial leisure. Its cultural significance is evidenced by the fact that it is both shaped by and has shaped the major trends of contemporary leisure (for example, privatisation, individualisation, commercialisation, rationalisation, hybridisation, simulation) and the fact that the practice of 'going to the gym' and 'working out' has now sparked off something of a cultural phenomenon by offering opportunities for physical activity from a variety of traditional institutionalised disciplines. Perhaps the most striking development, in terms of its cultural significance, however, is the fact that growth in the fitness industries has been strong worldwide (as opposed to being confined to the traditionally high-performing North American and European markets). And while one might seek to argue vehemently against the imposition of western values and bodily ideals upon other non-western cultures, it is a testament to the increasingly global appeal of the fitness movement (Datamonitor 2010, IHRSA 2010). 
The consensus position on health and fitness

More specific to the task of this article is the notion that the long-term success of the fitness industries is attributable (at least in part) to the simple fact that there now exists a wellsedimented position with respect to fitness and its relation to health. That is to say, support for the fitness industry is, in large part, linked to an overwhelmingly successful epistemological project (see Glassner 1990, Pronger 2002). Taking this into consideration, it might be useful to refer to this epistemological project as having spawned a consensus position. The consensus position rests upon two primary axes: (i) that fitness is multidimensional and (ii) that fitness is oriented, hierarchically, towards health as its higher order construct.

Fitness is multidimensional in the narrow sense insofar as it refers to a set or composite of attributes that people have or lack in varying degrees. For Casperson et al. (1985) for example, these attributes are divided into health-related and skill-related components and include such things as cardio-respiratory and muscular endurance, muscular strength, body composition and flexibility. It is multidimensional in the broader sense in that it implies that an individual has attained a set of characteristics and that they permit the good performance of a specified task in a given material and psycho-social environment (Bouchard and Shephard 1994). The characteristics underscored by Bouchard and Shephard are both healthrelated and skill-related. However, they include a broader range of morphological, motor, muscular, metabolic and cardiorespiratory components. For Casperson et al. and Bouchard and Shephard fitness is characterised as an individual phenomenon; a measure of individual bodily indices relative to acceptable and statistically verifiable parameters.

The second aspect of the consensus position is that fitness and health are conceived on hierarchical terms. In this hierarchy physical activity and exercise, fitness, and health are treated as discrete phenomena that are related to one another along a shared plane of causality, and following the logic that physical activity and exercise contribute to fitness, which contributes to positive health outcomes. It is notable here that, for both Casperson et al. and Bouchard and Shephard, it is the health-related components of fitness that are deemed to be the most important in this hierarchical configuration. That is to say, within the hierarchical model of health and fitness (a perhaps more appropriate name for the consensus position), it is health that functions as the most important goal or, more accurately, as the higher order construct. And that is to say that health is a logically independent phenomenon to which the predicate fitness is applied in a relative manner.

\section{The problematic of fitness}

Positions contrary to this consensus are more difficult to pin down (and, perhaps, are much less amenable to consensus). For one, that fitness is a cultural phenomenon is something that most would be willing to acknowledge. And secondly, the fact that the consensus position with respect to health and fitness is so conceptually embedded within a system of formal and informal inferences with respect to health means that the possibility of a critique is almost entirely negated.

In the interests of brevity, it might be said that the critics of this consensus position take both of these as its target. Since the emphasis in this article is on the relation of fitness to health, and since arguments about the cultural significance of the body and its fitness have been well rehearsed in existing sociological literature with respect to health (see for example, Foucault 1980, Lupton 1995, Nettleton 1995, Petersen 1997, Petersen and Lupton 1996), I confine myself to the following two remarks on the latter. For critics of fitness, at least, its 
cultural significance is blinded to a deeper political agenda insofar as its practices, discourses and institutions are set up in such a way that they align public health concerns with private projects of self-creation (Glassner 1989, 1990, Pronger 2002, Smith Maguire 2008, White et al. 1995). That is to say, the fitness field is set up in such a way that the burden of socially borne health risks are now directed towards the individual, and that these individuals are directed towards the market for their relief. Secondly, and on this basis, although there has been a tendency to see fitness as the new health - to see it as akin to what Petersen (1997: 197) referred to as the 'new social movement' with a primary concern to 'empower citizens' it has also been suggested that those progressivist convictions to social regeneration and collective self-improvement upon which the fitness field was built have now largely faded into insignificance. The fitness movement is criticised on the basis of the growing link between physical and consumption activity, the decline in emphasis on the use-value of the body in favour of its exchange- and sign-value, and for the general re-appropriation of its principal referent (that is, health) to meet capitalist objectives. The fitness movement is criticised for losing touch of its modernist illusions, or rather, for never adequately serving them in the first place.

Since the nature of the relation between fitness and health has received much less attention outside a medico-scientific context I would like to focus more specifically on the works of three authors who have discussed this in a sociological context. The following section focuses on the work of Smith Maguire $(2006,2008)$, Glassner $(1989,1990)$ and Bauman $(1998,2000)$.

\section{Health, fitness, and the problem of normativity}

The work of Smith Maguire $(2006,2008)$ has sought to grasp the problematic relation between fitness and health. In an earlier publication, for example, Smith Maguire explained that lived definitions of fitness are much less straightforward than the consensus position would lead one to believe, since they involve qualitative feelings of capacity, notions of control (over our bodies and how others see us), and socially constructed norms and expectations. For Smith Maguire, fitness is a complex concept with an awkward relation to health because, even though physical activity and exercise often make us fit according to the medico-scientific consensus, to look or feel fit is not always necessarily to be healthy. In later publications, this complexity is underscored again. However, the specific relation of fitness to health appears to have been supplanted by the more general question of whether or not fitness is good for us. In the final chapter of the book, Fit for Consumption: Sociology and the Business of Fitness, Smith Maguire (2008) asks the question, 'Is fitness good for us?' acknowledging that there is no 'yes or no' answer to this question. Rather, for most of those lower down the socioeconomic ladder - those who are more likely to be classed overweight or obese - the answer is a definitive no. This is because of a lack of consumption preferences that make the participation of this group unlikely and because of the ongoing withdrawal of subsidised public service facilities. Smith Maguire concludes that the commercial fitness field largely functions in a manner that reproduces the deeply entrenched, class-based stratification of health and health risks. And, in response to the aforementioned question then, it is only for a much smaller and more enfranchised segment of the population that the answer is yes (though even this turns out to be problematic on Smith Maguire's account).

Despite the broad and encompassing character of her initial questions, then, Smith Maguire's analysis actually turns out to be an analysis of whether or not the commercial fitness industries (or 'the fitness field') are good for us. The logic of the fitness industry (not necessarily the logic of fitness in a more general sense) has taken on the logic of consumption. That is to say, the fitness field now promotes a relation to the body that, in large part, encourages and permits the consumption of pleasures in other spheres such that, as Smith 
Maguire explains, we have become bodies fit to consume and fit to be consumed by others. To be sure, this might provide evidence that the vested interest of the fitness industries exist in an awkward relation to health. But this is quite different from saying that the logic of fitness more generally is now distinct from that of health. In fact, had Smith Maguire been more encompassing in defining what constitutes the fitness field, it is quite likely that her analysis and conclusions would have turned out to be quite different. Despite the fact that the insights into, and conclusions drawn about, the underlying assumptions of the consumer leisure market's framing of physical activity are both compelling and disconcerting, the initial question of fitness' problematic relation with health (and, indeed, the question of whether or not 'fitness is good for us') goes largely unanswered.

For others, the question of fitness' problematic relation to health is related to the use of the conjoined phrase 'health and fitness'. In particular, for Glassner and for Bauman, the use of the terms in this manner is a mistake. For Glassner (1990), although some fitness enthusiasts would be inclined (indeed, able) to distinguish between fitness and health, the two have become generally synonymous in their everyday and popular usage. Each term, Glassner explains, necessarily solicits the other, with the longer expression, 'health and fitness', invoked primarily when fitness enthusiasts want to draw specific attention to non-exercise components (that is, general activity levels or aspects of nutrition and diet). On this account then, one might say that, in the everyday usage of health and fitness there seems to be a sense of holism at play. Putting it in Rortyan (Rorty 1979) terms, it might be said that words like fitness take on their everyday meaning only insofar as they are related to other words like health (or diet, exercise, and physical activity) and not on the basis of any singularly representative character. Such a position, of course, implies, as Glassner explained, that people accept the well-confirmed medico-scientific evidence of the ameliorative and adaptive superiority of a strong, fat-free body. It implies the general uptake of something like the consensus position outlined in the previous section, which, today, seems entirely likely.

Contrary to such a holistic interpretation, Bauman $(1998,2000)$ is less eager to account for or rationalise the use of fitness and health in such a manner. Rather, with his analysis taking place within the context of liquid modernity, Bauman's effort highlights some profound differences between fitness and health and calls into question their commensurability and suitability of fit. Like Glassner, Bauman thinks that treating fitness and health synonymously is a mistake (perhaps even a category mistake, as we will see). And this is not merely for the "well-known fact that not all fitness regimes "are good for one's health" and that what helps one to stay healthy does not necessarily make one fit' (Bauman 2000: 77). Rather, for Bauman, health and fitness belong to two different discourses because they appeal to very different concerns about, and relations to, the body (the body and society).

For Bauman, since contemporary society needs neither the physical nor productive exertion required in earlier modes of sociality, it is the desire for consumption and not necessarily the demands of work that play the formative role in shaping individuals' relations to their bodies. On the basis of this shifting emphasis from being a society of producers to being a society of consumers, and since our present stage in the history of modernity has implicated individuals in a shift in concern from the ultimate ends in human life to pragmatic concerns about the optimal performance of means, fitness is depicted as having replaced health as the desired status of the human body. That is, as Bauman $(1998,2000)$ explained, since constant openness and an appeal to ever-greater levels of experience are the sine qua non of being integrated into this changing society, it is not the healthy body with its connotation of a steady state but the mobile, flexible, spontaneous and sensation-imbibing fit body that grasps the quality expected of modern individuals (or 'the experience-collector', Bauman 1998: 23). For Bauman (2000), fitness is revelatory of social life under modernity in its 
present, liquid stage because the fit body is multifunctional - driven by the principle of mobility and the logic of flows - and because it is anything but solid.

In spite of this emphasis, it is problematic for Bauman that fitness has replaced health as the desired normative status for individuals in modern society. ${ }^{2}$ This is due to the fact that fitness presents self-referential problems from which the norm of health was free (Bauman 1998: 23). ${ }^{3}$ Bauman explains this further:

[Health] is a norm, and norms are clearly delineated from above and below alike. 'Fitness' has perhaps its lower, though rather blurred and murky threshold, but cannot, by definition, have an upper limit; 'fitness' is, after all, about the constant ability to move further on, to rise to ever higher levels of experience. Hence 'fitness' will never acquire the comforting exactitude of a norm. 'Fitness' is a never-to-be-reached horizon looming forever in the future. (Bauman 1998: 23)

Fitness, then, is not merely reflexively mobilised (as would be the case with most categories under liquid modernity). Rather, it is reflexive by its very nature (by definition). Elsewhere, Bauman describes this inherent reflexivity in more detail:

If health is a 'no more and no less' type of condition, fitness stays permanently open on the side of 'more': it does not refer to a particular standard of bodily capacity, but to its (preferably unlimited) potential of expansion ... One may almost say that if health is about 'sticking to the norm', fitness is about the capacity to break all norms and leave every already achieved standard behind. (Bauman 2000: 77-8)

On this basis, Bauman concludes that, unlike the care for one's health, the pursuit of fitness has no natural or logical end. Since its targets can only be set in the context of a never-ending effort, the experience of fitness is often characterised by a perpetual sense of disappointment and anti-climax or, at best, the celebration of only momentary successes achieved thus far. The only thing fitness seekers know for sure, Bauman explains, is that they are not fit enough yet ('success thus far is but a short break before another round of hard work') (Bauman 2000: 78). Theirs is a logic of différance - of difference and perpetual deferral of gratification - because accounts of fitness have a naturally ambivalent character. The plight of the fitnessseeker, Bauman concludes, is one of perpetual self-scrutiny and self-reproach; an agony of which our health-seeking ancestors had no inkling.

Given the originality of Bauman's account of the relation between fitness and health, there is much value to be found in his characterisation of fitness as an ontologically mutable category. The broader implication of this is that fitness is, somewhat ironically, unfit for purpose (that is, that it cannot fulfil the normative role that is aspires to). Bauman is almost certainly correct in his assertion that, although a prime motive in the turning of our attention towards bodily fitness was meant to offer security and certainty in a radically disembedding socio-material environment, our preoccupation with matters of superficial embodiment has resulted (somewhat paradoxically) in the generation of more anxiety than less. On this basis, there is much merit in his more general argument for the dislocation of health and fitness. However, a caveat is necessary. That is, while it is fitness that is roundly criticised on Bauman's account, from my perspective it appears to be health that turns out to be the problematic category. In Bauman's account, health is something of a zombie category (to use Beck's phrase), embodying an outmoded horizon of experience that is logically incompatible with the radically disembedding character of an increasingly instrumental and consumptionoriented rationality. Fitness, though elusive by its very definition, is at the very least 
pragmatic in that it provides a means of becoming other and of reorienting the body and the self in the face of the consequences of modernity. On the basis of this distinction, a positive appropriation of Bauman's account is offered in the following sections.

\section{Considering a complemental model of health and fitness}

The relation of fitness to health is a complex one and there are problems to be encountered in both elevating health and dispensing with it to accommodate the concept of fitness. On the one hand, elevating health seems to imply making it an absolute concept; a characteristic that surely makes it an unserviceable goal. As Engelhardt (1975) aptly noted, how many people do you know that have ever achieved complete physical, mental and social wellbeing? One way of looking at this problem is to say that the main problem the supporters of the consensus position encounter is akin to the problem that has led Rorty (1998) towards a deflationary (or pragmatic) account of Truth (with a capital ' $T$ '). Rorty explained that justification (lower case) is relative to an audience and a range of truth candidates, but Truth is not relative to anything. It is only the relative, Rorty explains, about which there is anything to say. Correspondingly, one might just as easily say that, on the consensus position outlined earlier, it is fitness that is relative to a range of biomedical indicators, but health is not relative to anything. Not only does the consensus position make health an unserviceable goal, then, it makes the notion that fitness contributes to health a mere tautology.

One might grant that fitness is, indeed, multidimensional (though it need not be confined to certain avowed dimensions as Freund and Martin 2004 have shown). However, that it is related to health on hierarchical terms is much less clear. Or one might take a more hardnosed critical position and say that the multidimensional characterisation of fitness does nothing to violate its relational character, but the hierarchical structuring is (borrowing from Baudrillard) merely the vehicle of an egalitarian myth. One might grant the fact that preserving the health-fitness distinction is helpful in safeguarding health from being trivialised. But it might also be granted that such a distinction is merely blinding us to the logic of flows that characterise liquid modernity.

Although Bauman's position might appear more obviously plausible - and it is one, as will be seen, that does offer a workable alternative - his account, as it stands, is also subject to a number of difficulties. For one, Bauman (2000: 77) goes on to acknowledge that the status of all norms, 'the norm of health included', has been severely shaken and become fragile. And in this sense, bracketing concerns about the status of health in order to criticise fitness appears disingenuous at best, and the intellectual equivalent of having one's cake and eating it too at worst. A more fundamental problem, however, is the fact that the thoroughgoing futurity of his position is insensitive to what Throop (2010) has referred to as the 'vicissitudes of experience'. In exploring its multilayered character, for example, Throop (2010: 267) has argued that experience is best situated along a continuum of possible formulations, from the disjunctive immersion in the immediacy of practical activity to the mediacy of the conjunctive or distanced reflection events that have previously lapsed. These different temporal orientations, Throop (2010) explains, should be seen to affect a 'variegated structuring of experience' and, hence, to affect an alteration in a subject's mode of attention. On this basis, Throop concludes that:

while it is true that we often maintain an attitude toward the world that is structured according to a future orientation toward goals, projects, and desires ... it is also the case 
that there are moments where it is not merely attention to the future, but attention to the past or the contingencies of the present that directs our attention ... [I]t is often the case that individuals have little other choice than to deal with their immediate immersion in the present moment. (Throop 2010: 267-8)

For Throop then, Bauman's wholesale futurity would seem to privilege becoming over being, flux over stasis, activity over passivity, granularity over coherence and discordance over concordance at the expense of the relations between them. And it is this very privileging, Throop (2010: 212) explains, that negates the possibilities for understanding what he has referred to as dysphoric moments - broadly analogous to Heidegger's (1962: 103) concept of the 'un-ready-to-hand', Merleau-Ponty's (2002: 157) severing of the 'intentional arc', or Leder's (1990: 83) concept of 'bodily dys-appearance' - those 'world-destroying' moments in which the very sense of futurity is necessarily effaced.

In a general sense, this might be expanded to say that Bauman's position with respect to health and fitness negates the possibilities for understanding those situations in which individuals experience a modified temporality, and where it is the past or the present that is foregrounded in one's organisation of attention. In a more specific sense, it might be said that Bauman's position negates the possibilities for understanding those situations in which individuals' orientation towards their bodies change. It is certainly true that modern individuals' experiences of their embodied selves are structured according to being fit for the future and its possibilities. But surely, given the vulnerability and precariousness of human embodiment, individuals are not oriented towards the future in a wholesale manner. Rather, just as the body is something to be lived through in a subjective sense, it is also at times something to be maintained or rationalised, even something to be overcome or salvaged. Is it not the case that, with instances such as these, it is attention to the present objective status of the body at stasis that directs individuals' focus of attention? And is this not also tantamount to saying that, in certain instances, it is the health of the body (body-object) and not necessarily its fitness (as a body-subject) that becomes prominent?

\section{Health, fitness, and the complemental curve}

A possible way of reconciling the problems with the opposing positions discussed in this article is to make a number of modifications to Bauman's position, which I think is more plausible (especially because it appears to account for health on descriptive as opposed to absolute terms). Three points will suffice in outlining the contours and implications of this intermediary position. Firstly, one has to be clear on what Bauman means (or what he could mean by extension) by health and by fitness. Recall that, for Bauman, health and fitness appeal to discourses and relations to the body quite apart from one another. That is to say, whereas health can be delineated from above and below and is, thus, both an object of logic and epistemology; fitness (though perhaps having a lower threshold) is resistant to such conceptual determination and is, therefore, ontologically ambivalent. On this basis, one can take Bauman's distinction as having meant that health and fitness correspond to two specific planes of experience (on the basis of their appeal to different discourses) which can be represented graphically. Figure 1 shows a possible interpretation of Bauman's position.

On the basis of this illustration, it can be said that, where Health (upper case) corresponds to a bounded vertical (or epistemological) plane of experience upon which norms can be imposed, fitness (lower case) represents its boundless horizontal (or ontological) corollary which, by its very definition (and by itself), is resistant to any code of normativity. Contrary to Bauman's original formulation, this illustration retains the importance of Health. Following Leder (1992), Health is taken to correspond to the mechanistic body-object that 


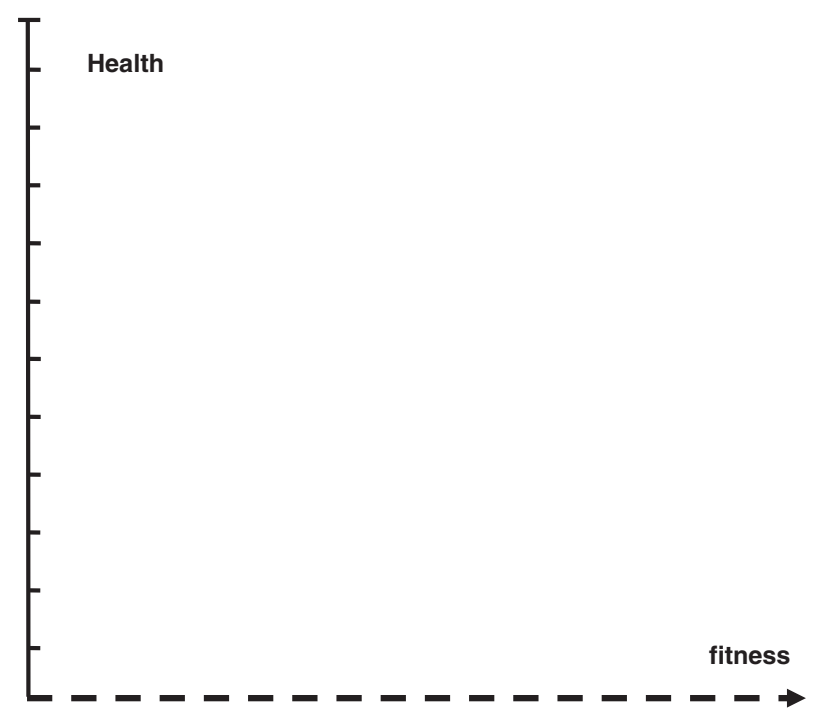

Figure 1: The planes of the Health and fitness experience

medical thought and practice presuppose whereas fitness, on the other hand, is designated by the phenomenological or lived body-subject.

Secondly, it is important to outline the conditions for an alternative conception on how Health and fitness might be thought to interact. Rather than treating Health and fitness in a causal relationship (as supporters of the consensus position do) or dislocating them (as Bauman appears to want to do) it will be more instructive to say that Health and fitness exist in a complemental relation. Leder's (1990) use of Freud's complemental series is helpful here. The complemental series exhibits two important characteristics. Firstly, it provides a heuristic whereupon a gradated series of phenomena, experiences, or cases can be plotted between what have seemed to be intractable positions. Secondly, with the complemental series, it is to be observed of the phenomena involved that an increase in one factor necessarily correlates with a decrease in the other. As Freud (2000) originally explained, there is no reason to deny the existence of seemingly opposing cases at the two ends of the series. However, in order to cover most of the cases in between, it will be observed that the diminishing intensity of one factor is balanced by the increasing intensity of the other. As regards their relation then, rather than exhibiting a causal structure - which precludes an understanding of that peculiarly phenomenological tension that exists between the experience of one's body as both an object and subject - the complemental model depicts a figure-ground structure whereupon Health and fitness interact at various levels. This figure-ground structure, again, can be represented graphically as is shown in the Figure 2.

By joining $\mathrm{H}^{30}$ to $\mathrm{f}^{1}, \mathrm{H}^{29}$ to $\mathrm{f}^{2}, \mathrm{H}^{28}$ to $\mathrm{f}^{3}, \mathrm{H}^{27}$ to $\mathrm{f}^{4}$, and so on in an inverse manner, the model depicts a complemental curve whereupon varying degrees of prominence can be attributed to both Health and to fitness at the same time. That is to say, the complemental curve provides a means of accounting for both the body's objective and subjective dimensions and for the mapping of a whole host of what Throop (2009: 536) has referred to as 'intermediary varieties of experience' in between. ${ }^{4}$

Thirdly, by plotting points of intersection along the curve - dots plotted on the curve at $\left(\mathrm{H}^{21}, \mathrm{f}^{1}\right),\left(\mathrm{H}^{11}, \mathrm{f}^{5}\right),\left(\mathrm{H}^{5}, \mathrm{f}^{12}\right)$ and $\left(\mathrm{H}^{1}, \mathrm{f}^{22}\right)$ which might usefully be referred to as fixational 


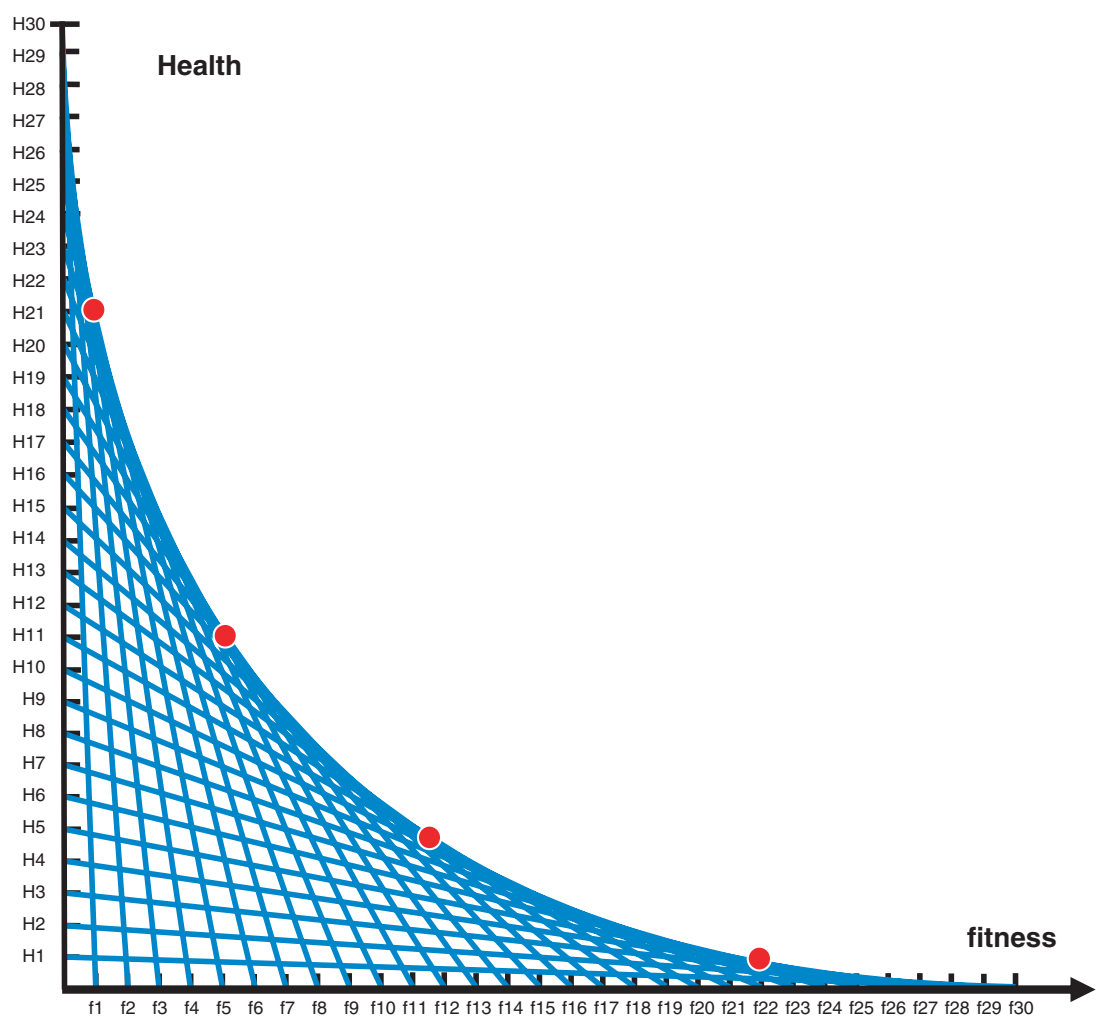

Figure 2: The complemental curve

junctures - the model suggests two important final things. Firstly, with the complemental model, an increase in fitness along the horizontal axis does not imply an increase in Health on the vertical one, as would traditionally be the case. Rather, engaging the lived bodysubject through fitness should be seen as rendering at varying levels of backgrounded awareness Health and the body-object it presupposes..$^{5}$ And secondly, in the complemental model, Health should be seen to function as a 'narrative mode of comprehension' (Ricoeur 1984: 159). That is, it enables us to cope with the logic of flows that characterise fitness in a manner that promotes what Ricoeur (1984: 66) referred to as a 'concordant discordance'. That is to say, its vertical character cuts through the temporally ambivalent character of fitness in such a way that the succession of episodic sequences can be thought of, not merely as 'one thing after another', but, rather, as 'one thing because of another' (1984: 52). This emphasis on concordance over discordance is of particular value in ameliorating those hermeneutical problems outlined in the previous section, problems associated with the oftexperienced indeterminacy, frailty, and precariousness of human embodiment. One might go as far as to say that the success of the biomedical model is a product of what Ricoeur (1984: 31) has referred to as the mythopoeic triumph of concordance over discordance. Moreover, it is perhaps only through an immersion in activities that Leder (1990: 166) has described as having ecstatic qualities (or promoting the 'one-body') that the vertical character of Health and the body-object it presupposes can become entirely effaced. Only then can a space be opened up for the free play of the centrifugal, ecstatic fit body-subject without reservation or arrest. 


\section{Conclusion}

This article has been based on the premise that the concept fitness and, in particular, its relation to health has been the subject of much recent critical attention. Given this, it was observed that there has been a general tendency for scholarship in this area to make either one of two claims: (i) that fitness and health are causally related (that is, that there is a simple linear relationship between physical activity and exercise for fitness and positive health outcomes) or (ii) that this is merely illusory (that is, that aligning fitness and health is a deeply political project, it does little more than service the economic interests of the broader fitness industries, and, as such, fitness is something quite apart from health). Importantly, it was also observed that there has been little in the way of exchange between these two opposing positions which, despite the shared context of their subject matter, have come from functionally separate parts of the academy. On this basis, and on the basis of a number of observed inadequacies with both of these positions, the purpose of this article was to engage with these perspectives and explore the possibilities for proposing an alternative. While it is unclear as to whether an article like this could offer a means of reconciling the resulting impasse between scholarly disciplines, I hope that by engaging with these opposing viewpoints it has been effective in doing at least two things.

Firstly, the article lamented that debates about fitness have often descended into polemic. It endeavoured to take seriously the claim that there is a relation between fitness and health while also acknowledging the fact that there is something wrong with the nature of the relation as it is presently conceived. That is to say, the arguments put forward in this article have endeavoured to take seriously the claim (contrary to Smith Maguire's) that fitness is good for us, while also acknowledging that this good need not necessarily be health. It was shown that, while the notion that what is good in terms of fitness is quite apart from what is good in terms of Health (or rather, that fitness and Health correspond to separate planes of experience, as I have said) was already present in Bauman's analysis, that they can be equally valid (especially in the context of our present stage in the history of liquid modernity) was much less apparent in this work. ${ }^{6}$ On this basis, it was argued that a lack of a common good between fitness and health should in no way be seen to negate the possibility for exploring the relation between them (as Bauman would appear to suggest). Rather, it just meant that it had to be conceived of on new terms.

Secondly, and in response to this relational assignment, this article has contributed to the growing literature on the sociology of health and fitness by examining the possibilities for a redescription of the relation between fitness and Health. In effect, it has offered another plausible description of what Freund and Martin (2004) have referred to as the relational model of fitness. Rather than treating fitness and Health on hierarchical terms, and without advocating a view that would resign the latter to the conceptual wastebasket, the complemental model described in this article acknowledged the importance of the embodied subject while also acknowledging the fact that there exists a whole host of intermediary varieties of experience in which we can (or, indeed, are forced to) reflect upon and become mindful of our bodies as objects. That is to say, in reconfiguring the relation of fitness to Health, the complemental model has taken into account the fact that the body is a functional gestalt, both subject and object, a site of representation and practice, over-exposed and under-exposed, attuned to multiple temporal orientations, and characterised by a series of absent-present relations. In a general sense then, in its examination of the relation of fitness and Health, this article has taken very seriously what Eagleton (1993) meant when he said that, while it is not quite true that I have a body, it is not quite true that I am one either. On 
this basis, future empirical research would do well to consider more specifically the variegated structuring of bodily experience that traverses the complemental curve. This requires an examination of the extent and conditions under which an individual's orientation towards their body changes. In fact, it implies that a further examination of the extent and conditions under which the body is amenable to change more generally is needed.

Of particular importance in the context of this article's two main contributions is the need for further consideration with respect to how to talk about the fit body, which, in the context of an increasingly emphasised dual structure of the phenomenological body, has not been adequately explored. It is clear that we have not yet come to terms with the task of talking about the fit body and the extent of its somatic potential to affect and be affected. Freund and Martin's (2004) social ecology of fitness (of en-abling bodies) is a noteworthy contribution. It is noteworthy insofar as it begun in shifting the emphasis away from individual fitness and the substantive 'I am' to a notion of fitness and the fit body that is grounded in terms of contextualised abilities (an 'I can') and the relations of fit between individuals and their socio-material environments. However, in order to build on this shifting emphasis, there is a need for future research to focus on a broader range of objects, artefacts, techniques, technologies and subjects that (following Latour 2004b) might be thought of as contributing to the progressive articulation of the fit body-subject, thus en-abling it and making it possible for individuals to inhabit the world in new ways.

Address for correspondence: Ross D. Neville, College of Arts and Tourism, Dublin Institute of Technology, Cathal Brugha Street, Dublin, Ireland

E-mail: ross.neville2@mydit.ie

\section{Acknowledgements}

I would like to acknowledge the support of the Dublin Institute of Technology's ABBEST PhD Research Scholarship (September 2007 to March 2011) and my supervisory team, Catherine Gorman (Dublin Institute of Technology), Sheila Flanagan (Dublin Institute of Technology) and Frederic Dimanche (School of Knowledge Economy and Management Business School). I would also like to acknowledge the reviewers' helpful comments and suggestions which I hope to have incorporated sufficiently.

\section{Notes}

1 For example, in 2008 Hans Muench (IHRSA Director Europe) noted that, for over the last 20 years, the fitness industry has grown consistently and has proved itself to be recession resilient (quoted in Amend 2008). Even more recent figures, despite declining economic conditions, have not shown this to be untrue (IHRSA 2010).

2 Bauman's articulation of the problem of fitness can be divided into three main themes: the problem of normativity, perspective, and interpersonal comparison. For the purposes of this article, and in the interests of the space constraints that apply, the focus of attention is on the first.

3 Bauman's account of health is typically Boorsian in that it aligns with Boorse's (1977) classification of health as normal functional ability.

4 One thinks of Fox's (2002) characterisation of the growing body, the becoming-fit body, the cancerous body, the valetudinarian body and the dying body as useful examples of this series of intermediary varieties of experiencing one's body along the complemental curve. 
5 This resonates particularly well with Boorse's (1977) distinction between intrinsic and instrumental or positive health (between normal functional ability and what is beyond it). In this distinction, Boorse, too, considers whether there is a causal relation between fitness and health or, rather, if physical fitness merely effects a resistance to disease. Boorse appears to tend towards the latter view. Someone with a high level of physical fitness (however differently he might have defined the terms) might certainly be thought of as being healthier than someone without such a high level. However, this is due to the former's increased ability to resist disease and not due to any increase in intrinsic health.

6 For an account of how fitness practices can acquire specific meanings for participants over time, see Crossley $(2004,2006,2008)$ and Sassatelli (1999a, 1999b).

\section{References}

Amend, P. (2008) Hans Muench celebrates his return to IHRSA as the new director, Europe, Club Business Europe, January/February, 15-17.

Bauman, Z. (1998) On postmodern uses of sex, Theory, Culture \& Society, 15, 3-4, 19-33.

Bauman, Z. (2000) Liquid Modernity. Cambridge: Polity Press.

Boorse, C. (1977) Health as a theoretical concept, Philosophy of Science, 44, 4, 542-73.

Bouchard, C.E. and Shephard, R.J. (1994) Physical activity, fitness, and health. In Bouchard, C.E., Shephard, R.J. and Stephens, T. (eds) Physical Activity, Fitness, and Health: International Proceedings and Consensus Statement. Champaign, IL: Human Kinetics.

Casperson, C.J., Powell, K.E. and Christenson, G.M. (1985) Physical activity, exercise, and physical fitness: definitions and distinctions for health-related research, Public Health Reports, $100,2,126-31$.

Crossley, N. (2004) The circuit trainer's habitus: reflexive body techniques and the sociality of the workout, Body \& Society, 10, 1, 37-69.

Crossley, N. (2006) In the gym: Motives, meaning and moral careers, Body \& Society, 12, 3, 2350.

Crossley, N. (2008) (Net)working out: Social capital in a private health club, British Journal of Sociology, 5, 3, 475-500.

Datamonitor. (2010) Leisure Facilities Industry Profile. London: Datamonitor Europe.

Eagleton, T. (1993) It is not quite true that I have a body, and not quite true that I am one either, London Review of Books, 15, 10, 7-8.

Engelhardt, T. (1975) The concepts of health and disease. In Engelhardt, T. and Spicker, S.F. (eds) Evaluation and Explanation in the Biomedical Sciences. Dordrecht: D. Reidel.

Foucault, M. (1980) The politics of health in the eighteenth century. In Gordon, C. (ed.) Power/Knowledge: Selected Interviews \& Other Writings, 1972-1977, by Michel Foucault. New York: Pantheon Books.

Fox, N.J. (2002) Refracting 'health': Deleuze, Guattari and body-self, Health, 6, 3, 347-63.

Freud, S. (2000) Three Essays on the Theory of Sexuality. New York: Norton.

Freund, P. and Martin, G. (2004) Walking and motoring: fitness and the social organisation of movement, Sociology of Health \& Illness, 26, 3, 273-86.

Glassner, B. (1989) Fitness and the postmodern self, Journal of Health and Social Behavior, 30, 2, $180-91$.

Glassner, B. (1990) Fit for postmodern selfhood. In Becker, H.S. and McCall, M.M. (eds) Symbolic Interaction and Cultural Studies. Chicago: University of Chicago Press.

Heidegger, M. (1962) Being and Time. Oxford: Blackwell.

International Health, Racquet and Sportsclub Association (IHRSA) (2010) The IHRSA Global Report 2010. Boston: IHRSA.

Latour, B. (2004a) Why has critique run out of steam? From matters of fact to matters of concern, Critical Inquiry, 30, 2, 225-48. 
Latour, B. (2004b) How to talk about the body? The normative dimension of science studies, Body \& Society, 10, 2-3, 205-29.

Leder, D. (1990) The Absent Body. Chicago: University of Chicago Press.

Leder, D. (1992) A tale of two bodies: the Cartesian corpse and the lived body. In Leder, D (ed.) The Body in Medical Thought and Practice. Dordrecht: Kluwer.

Lupton, D. (1995) The Imperative of Health: Public Health and the Regulated Body. London: Sage.

Merleau-Ponty, M. (2002) Phenomenology of Perception. London: Routledge.

Nettleton, S. (1995) The Sociology of Health and Illness. Oxford: Polity Press.

Petersen, A. (1997) Risk, governance and the new public health. In Petersen, A. and Bunton, R. (eds) Foucault, Health, and Medicine. London: Routledge.

Petersen, A. and Lupton, D. (1996) The New Public Health: Health and the Self in the Age of Risk. London: Sage.

Pronger, B. (2002) Body Fascism: Salvation in the Technology of Physical Fitness. Toronto: University of Toronto Press.

Ricoeur, P. (1984) Time and Narrative: Volume 1. Chicago: University of Chicago Press.

Rorty, R. (1979) Philosophy and the Mirror of Nature. Princeton: Princeton University Press.

Rorty, R. (1998) Truth and Progress. Cambridge: Cambridge University Press.

Sassatelli, R. (1999a) Interaction order and beyond: a field analysis of body culture within fitness gyms, Body \& Society, 5, 2-3, 227-48.

Sassatelli, R. (1999b) Fitness gyms and the local organization of experience, Sociological Research Online, 4, 3, available at http://www.socresonline.org.uk/4/3/sassatelli.html (last accessed 12 April 2012).

Smith Maguire, J. (2006) The culture of fitness - opportunities and challenges for health. In Proceedings of the International Sports Marketing Conference: Marketing Sports and Physical Activity - Impacts on Health and Leisure. Hong Kong: Hong Kong Baptist University, available at https://lra.le.ac.uk/handle/2381/7706 (last accessed 21 April 2012).

Smith Maguire, J. (2008) Fit for Consumption: Sociology and the Business of Fitness. London: Routledge.

Throop, C.J. (2009) Intermediary varieties of experience, Ethnos, 74, 4, 535-58.

Throop, C.J. (2010) Suffering and Sentiment: Exploring the Vicissitudes of Experience and Pain in Yap. Berkeley: University of California Press.

White, P., Young, K. and Gillett, J. (1995) Bodywork as a moral imperative: some critical notes on health and fitness, Society and Leisure, 18, 1, 159-82. 